\title{
Clinical value of full-length tryptophanyl-tRNA synthetase for sepsis detection in critically ill patients-A retrospective clinical assessment
}

\section{Ji Soo Choi}

Yonsei University College of Medicine

\section{Bo Ra Yoon}

Yonsei University College of Medicine

Ju Hye Sin

Yonsei University College of Medicine

\section{Su Hwan Lee}

Yonsei University College of Medicine

Ah Young Leem

Yonsei University College of Medicine

Moo Suk Park

Yonsei University College of Medicine

Young Sam Kim

Yonsei University College of Medicine

Kyung Soo Chung ( $\nabla$ chungks@yuhs.ac)

Yonsei University College of Medicine https://orcid.org/0000-0003-1604-8730

\section{Research}

Keywords: Tryptophanyl-tRNA synthetase, sepsis, mortality, intensive care unit

Posted Date: January 2nd, 2020

DOI: https://doi.org/10.21203/rs.2.19877/v1

License: (c) (i) This work is licensed under a Creative Commons Attribution 4.0 International License. Read Full License

Version of Record: A version of this preprint was published at International Journal of Infectious Diseases on August 1st, 2020. See the published version at https://doi.org/10.1016/j.ijid.2020.05.105. 


\section{Abstract}

Background

Sepsis is associated with high mortality, and the related innate immune system activation and diagnostic factors are not fully understood. This study aimed to statistically analyse the clinical value of full-length tryptophanyltRNA synthetase (WRS) induced through inflammatory stimuli in the detection of sepsis and mortality prediction in critically ill patients.

Method

In this retrospective analysis, we prospectively collected blood samples from patients in the medical intensive care unit (ICU) at Yonsei University College of Medicine, from March 2015 to June 2018. Sepsis detection and mortality prediction using WRS levels were compared to that with procalcitonin (PCT), C-reactive protein (CRP), and interleukin-6 (IL-6) levels, and with Sequential Organ Failure Assessment (SOFA) and Acute Physiology and Chronic Health Evaluation II (APACHE II) scores, using area under the receiver operating characteristic curve (AUROC) and Cox proportional-hazards and Kaplan-Meier survival analyses.

Results

We enrolled 241 study patients, of whom 190 (78.8\%) had been diagnosed with sepsis on ICU admission. The AUROCs for sepsis discrimination with WRS, PCT, CRP, and IL-6 levels, and SOFA and APACHE II scores were $0.864,0.727,0.625,0.651,0.840$, and 0.754 , respectively. The prediction of 28-day mortality in patients with sepsis using WRS levels was possible and non-inferior to that with the SOFA score (WRS vs. SOFA, AUROC 0.687 vs. $0.711 ;$ AUROC difference, $0.024 ; P=0.650$ ).

Conclusions

WRS secreted early in sepsis may be useful not only for early detection of sepsis but also for mortality prediction in critically ill patients.

\section{Background}

Sepsis is a major clinical challenge in critically ill patients, involving high morbidity and mortality [1]. Early diagnosis and comprehensive treatment are important for survival in sepsis patients [2]; however, the most appropriate diagnostic criteria and treatment remain controversial [3]. The Third International Consensus Definitions for Sepsis and Septic Shock (Sepsis-3) introduced the extent of organ damage into the definition for sepsis, using the Sequential Organ Failure Assessment (SOFA) score for assessing the dysregulated immune responses to invasive infection based on mortality [4]. However, whether sepsis has been caused by an infection is still determined based on a clinician's opinion [5]. Although markers, such as procalcitonin (PCT) and C-reactive protein (CRP), are used to determine infection [6], these markers are limited in that they cannot detect fungal and viral infections $[7,8]$. Therefore, a biomarker is needed to reflect the infection-related immune response, including that in cases of bacterial, fungal, and viral infections, and to predict mortality while meeting the new Sepsis-3 definition. 
Innate immunity is activated through the interaction between exogenous molecules such as pathogen-associated molecular patterns and pattern-recognition receptors such as toll-like receptors and C-type leptin receptors [9-11]. However, intrinsic factors of innate immunity in humans involved in defence against external infections remain unknown. Full-length tryptophanyl tRNA synthetase (WRS), which is present in human monocyte cytoplasm, is an important housekeeping enzyme that participates in the translation of messenger RNA (mRNA), but the function and precise mechanisms of WRS are unclear [12]. Previous studies have reported that WRS is rapidly released in case of pathogenic bacterial and viral infections [13-16]. However, clinical research evaluating the prognostic implications of WRS for the diagnosis of sepsis and its association with mortality in patients with sepsis is lacking.

This study aimed to evaluate the clinical value of WRS, induced through inflammatory stimuli, in sepsis detection and mortality prediction in critically ill patients.

\section{Methods}

\section{Study design and patient population}

This study was a retrospective analysis of prospectively collected blood samples from patients who had been admitted to the medical intensive care unit (ICU) at Yonsei University College of Medicine from March 2015 to June 2018. In total, 340 patients aged $>18$ years who had been admitted to the medical ICU initially provided their informed consent to participate in this study. We excluded 99 patients comprising 76 patients who withdrew their consent, 12 patients who were re-admitted, and 11 patients who were lost to follow-up. Finally, 241 patients aged $>18$ years old were enrolled. We analysed WRS reference values using residual samples from randomly selected 127 healthy individuals who had tested the blood examination for health checkups (Fig. 1).

The study protocol was approved by the Institutional Review Board (IRB) of Severance Hospital (IRB number: 42017-0654, 4-2013-0585) for examining the inflammation and sepsis groups. For the healthy control group, the specimens used in this study were distributed by the Korea Institute of Radiological and Medical Sciences Radiation Biobank in the Republic of Korea (IRB number: P01-201803-31-006). Informed consent was waived because of the retrospective design of the study.

\section{Variables and definitions}

Using the Sepsis-3 definition [4], sepsis was defined as life-threatening organ dysfunction due to a dysregulated host response to infection, and the SOFA score was used to assess organ dysfunction. Therefore, we defined sepsis as an increase of $\geq 2$ points in the SOFA score in patients with suspected infection, and inflammation was defined as a systemic response other than that due to infection.

\section{Data collection and clinical outcomes}

The levels of biomarkers, such as WRS, PCT, CRP, and interleukin-6 (IL-6), were measured using blood samples collected at the time of ICU admission from consenting patients. Other laboratory findings, the SOFA score, and the Acute Physiology and Chronic Health Evaluation II (APACHE II) score were analysed using data obtained within 24 hours of ICU admission. We reviewed electronic medical records to obtain data concerning baseline demographics and pre-existing comorbidities, and we diagnosed patients with sepsis or inflammation according to the Sepsis-3 definition. 
First, we compared the sepsis discrimination power of WRS to that of the other biomarkers. Second, the predictive power of WRS for 28-day mortality was compared with that of the SOFA and APACHE II scores.

\section{Tryptophanyl tRNA synthetase analysis}

Concentration of WRS in human serum was analysed using a human WRS ELISA kit (category no. JWBS-R001) manufactured by JW Bioscience (Chungcheongbuk-do, South Korea), in accordance with the manufacturer's instructions. Briefly, polystyrene 96-well plates (Nunc Immunoplate, Nunc, Denmark) were coated with $100 \mu \mathrm{L}$ of affinity-purified coating antibody, covered with plate sealer, and incubated for 15 hours at $4{ }^{\circ} \mathrm{C}$. After incubation, the plates were washed to remove unbound antibodies, then the remaining binding sites in the plate were blocked using incubation for 1 hour with a blocking buffer. The blocking buffer was then aspirated, and standard and diluted samples were added to designated wells for 1 hour at room temperature. Plates were washed with washing buffer, and $100 \mu \mathrm{L}$ of horseradish peroxidase-conjugated detection antibody was added to each well. After the incubation period, plates were washed with washing buffer. After washing, 3, 3', 5, 5'-

tetramethylbenzidine reagent $(50 \mu \mathrm{L} /$ well) was added and incubated for $10 \mathrm{~min}$ at room temperature in darkness. The colour reaction was stopped by adding $50 \mu \mathrm{L}$ of stop solution to all wells. The plate was read at $450 \mathrm{~nm}$ on a spectrophotometric microplate reader (Sunrise, Tecan, Grödig, Austria). The WRS concentration in each sample was calculated from the standard curve (linear regression equation).

\section{Interleukin-6 analysis}

Serum samples were analysed using a Human IL-6 Quantikine ELISA kit (D6050) purchased from R\&D Systems (Minneapolis, MN, USA), in accordance with the manufacturer's instructions. Briefly, assay diluent (100 $\mu \mathrm{L})$ and a sample $(100 \mu \mathrm{L})$ were added into each well of the 96 -well ELISA plate and incubated for 2 hours at room temperature. The plate was then thoroughly washed four times with wash buffer to remove any unbound enzymelabelled antibodies. Subsequently, detection antibody $(200 \mu \mathrm{L} /$ well $)$ was added and incubated for 2 hours at room temperature. After washing four times, substrate reagent (200 $\mu \mathrm{L} /$ well) was added and incubated for 20 min at room temperature in darkness. To terminate the reaction, stop solution ( $50 \mu \mathrm{L} /$ well) was added and the absorbance was measured at $450 \mathrm{~nm}$. The standard curve of IL-6 ELISA was established using 4-parameter logistic regression calibration models.

\section{C-reactive protein analysis}

The CRP levels were measured using CRP kits purchased from JW Bioscience on a Hitachi 7180 auto-analyser (Hitachi Ltd., Tokyo, Japan). All samples were analysed in duplicate.

\section{Procalcitonin analysis}

The PCT levels were measured using an Elecsys BRAHMS PCT kit on a Modular E170 analyser (Roche Diagnostic, Mannheim, Germany).

\section{Statistical analysis}

We analysed clinical parameters using the Mann-Whitney $U$ test for continuous variables and chi-squared or Fisher's exact tests for categorical variables. Continuous variables are expressed as medians with interquartile ranges and categorical variables as numbers with percentages. 
Sepsis discrimination and 28-day mortality prediction were performed using the area under receiver operating characteristic curve (AUROC). Patients were then divided into mortality low- and high-risk groups according to WRS cut-off values, and the Kaplan-Meier survival curves of each group were compared. Statistical analyses were performed using R Statistical Software, version 3.4.1 (The R Foundation for Statistical Computing, Vienna, Austria).

\section{Results}

\section{Baseline characteristics of the study population}

Of the ICU cohort, 241 patients were finally enrolled in this study and the sepsis incidence rate was $78.8 \%(\mathrm{~N}=$ 190). The patients were divided into two groups, namely, inflammation and sepsis groups, according to the Sepsis-3 definition, and patient baseline demographics are described in Table 1. Age, sex, body mass index (BMI), and pre-existing comorbidity were not found to be significantly different between the groups. However, compared to the inflammation group, the incidence of acute kidney injury (AKI) was higher in the sepsis group (12 vs. 87 patients; $P=0.004)$. Poorer results for blood urea nitrogen $(20.5 \mathrm{vs} .34 .2 \mathrm{mg} / \mathrm{dL} ; \mathrm{P}=0.001)$ and creatinine $(0.87$ vs. $1.61 \mathrm{mg} / \mathrm{dL} ; P=0.003$ ) levels were found in the sepsis group. The hemodynamic variables were found to be more unstable in patients with sepsis (mean arterial pressure, 90 vs. $73 \mathrm{mmHg} ; \mathrm{P}=0.008$; heart rate, 96 vs. 113 beats/min; $P<0.001)$. There was no difference in the white blood cell (WBC) and haematocrit levels, but higher red cell distribution width ( 14.8 vs. $15.6 \% ; P=0.016)$ and lower platelet $(191$ vs. $118 \times 103 / \mu \mathrm{L} ; \mathrm{P}<0.001)$ and higher lactate ( 1.7 vs. $2.5 \mathrm{mmol} / \mathrm{L} ; \mathrm{P}<0.001)$ levels were observed in the sepsis group. Albumin level was higher in the inflammation group ( 2.6 vs. $2.4 \mathrm{~g} / \mathrm{dL} ; \mathrm{P}=0.004$ ), whereas the total bilirubin level was higher in the sepsis group ( 0.6 vs. $0.8 \mathrm{mg} / \mathrm{dL} ; \mathrm{P}=0.025$ ); both total bilirubin levels were within the normal range (reference, $0.4-$ $1.5 \mathrm{mg} / \mathrm{dL}$ ). In terms of electrolytes, sodium and potassium showed the same median values and did not differ significantly.

Biomarkers, previously shown to increase due to sepsis, were measured in both the healthy controls as well as in the ICU cohort patients (Table 2). WRS, PCT, CRP, and IL-6 levels became progressively higher when we analysed the healthy controls, inflammation, and sepsis groups: WRS (healthy control vs. inflammation vs. sepsis, 18.36 vs. 44.04 vs. $86.60 \mathrm{ng} / \mathrm{mL}$; $P<0.001), P C T$ (could not be measured vs. 0.40 vs. $2.82 \mathrm{ng} / \mathrm{mL} ; \mathrm{P}<0.001), C R P(0.06$ vs. 8.46 vs. $12.92 \mathrm{mg} / \mathrm{L} ; \mathrm{P}=0.006)$, and IL-6 (2.01 vs. 109.00 vs. $282.00 \mathrm{pg} / \mathrm{mL} ; \mathrm{P}=0.001)$. The SOFA scores (6 vs. $10 ; \mathrm{P}<0.001)$ and APACHE II scores (19 vs. $27 ; \mathrm{P}<0.001)$ at the time of ICU admission were higher in the sepsis group. The results showed a statistically significant difference with respect to mortality and other clinical outcomes: 28 -day mortality (inflammation vs. sepsis, $13.7 \%$ vs. $35.8 \%$; $P=0.003)$, ICU mortality $(17.6 \%$ vs. $35.8 \%$; $P=0.014)$, hospital mortality ( $14 \%$ vs. $89 \% ; P=0.013)$, ICU length of stay ( 6 days vs. 9 days; $P=0.039$ ), and ICUfree days ( 21 days vs. 11 days; $P<0.001)$.

\section{Comparison of sepsis discrimination power}

We compared the sepsis discrimination power of WRS to that of PCT, CRP, IL-6, SOFA, and APACHE II (Fig. 2, Table 3) results. The sepsis discrimination power of all variables was statistically significant $(P<0.05)$. The AUROCs were $0.864,0.727,0.625,0.651,0.840$, and 0.754 for WRS, PCT, CRP, IL-6, SOFA, and APACHE II results, respectively. The AUROC of WRS was higher than that of the PCT level (AUROC difference, $0.137 ; P=0.013$ ), CRP level $(0.239 ; P<0.001)$, IL-6 level $(0.213 ; P<0.001)$, and APACHE II score $(0.110 ; P=0.021)$, and the difference was 
statistically significant. Compared with the SOFA score, the WRS level showed a higher AUROC, but this difference was not statistically significant $(0.024 ; \mathrm{P}=0.576)$. The cut-off value for the WRS level for sepsis discrimination was $54.34 \mathrm{ng} / \mathrm{mL}$.

\section{Mortality prediction and clinical outcomes}

In terms of 28-day overall mortality, prediction with the PCT (AUROC, 0.519; P = 0.672) and CRP $(0.436 ; P=0.414$ ) levels was not statistically significant. The AUROC of the WRS level $(0.687 ; P<0.001)$ was lower than that of the SOFA score $(0.711 ; P<0.001)$; however, the difference was not statistically significant $(-0.024 ; P=0.650)($ Fig. 3 , Table 4).

The cut-off value for the WRS level was $97.23 \mathrm{ng} / \mathrm{mL}$ for the prediction of 28-day mortality. The 28-day overall mortality was also compared between low- and high-risk groups using a Kaplan-Meier curve (Fig. 4). The mortality rate in the high-risk group was $56.4 \%$, which was higher than that in the low-risk group (hazard ratio, 1.015; 95\% confidence interval, 1.009-1.021; log rank test, $\mathrm{P}<0.001$ ).

\section{Discussion}

In this study, WRS levels progressively increased in the following group order: healthy controls, inflammation group, and sepsis group, along with the levels of other biomarkers previously considered to indicate sepsis, namely, PCT, CRP, and IL-6. The AUROC for sepsis discrimination of WRS was also higher than the AUROCs for other factors such as PCT, CRP, and IL-6 levels, and the SOFA and APACHE II scores. The AUROC of WRS for predicting 28-day overall mortality was not found to be inferior to that of the SOFA score. Furthermore, based on AUROC analyses, the cut-off values of the WRS level for sepsis discrimination and 28-day mortality prediction were $53.34 \mathrm{ng} / \mathrm{mL}$ and $97.23 \mathrm{ng} / \mathrm{mL}$, respectively.

The recently revised Sepsis-3 definition defines sepsis as a dysregulated host response to pathogenic infection, leading to life-threatening organ dysfunction. This definition is focused on organ damage from dysregulated immune responses due to invasive infection [4]. Furthermore, in the 2018 updated Surviving Sepsis Campaign Bundle, the guidelines changed from 3-hour and 6-hour bundles to a 1-hour bundle. The guidelines further pointed to the need for urgent assessment and treatment in patients with sepsis [17], indicating that an initial diagnosis is essential to manage sepsis [18]. Other previous studies have shown that CRP and IL-6 levels could be helpful for a diagnosis of sepsis; however, their strength in the diagnosis of sepsis has been controversial [19-21]. In our study, the sepsis discrimination power of the CRP and IL-6 levels was lower than that of the other variables. Furthermore, many previous studies have investigated novel clinical biomarkers, such as IL-27, presepsin, angiopoietin-1, and high mobility group box 1, as diagnostic factors for sepsis [22-24]; however, determining a standard test for sepsis remains a challenge.

PCT is released within 3-4 hours after infection or injury [25], and has been widely considered as a highly predictive diagnostic marker in patients with sepsis with distinguishable specificity for bacterial infection [26]. However, PCT levels cannot distinguish between fungal or viral infections and bacterial infections $[8,27]$. Furthermore, some studies have reported that PCT levels have not always been good predictors of sepsis-related prognosis [28], and the determination of changes in the PCT levels is needed rather than a single PCT level measurement, to predict mortality in patients with sepsis [29]. In our study, the sepsis discrimination power of PCT was found to be higher than that of other variables, but not with respect to 28-day overall mortality. 
The SOFA score has been shown to be helpful in predicting in-hospital mortality in patients with sepsis [30]. Our study findings also showed that SOFA scores correlated with sepsis diagnosis and 28-day overall mortality. However, the use of this score to identify patients with sepsis has also been challenged [31]. While the SOFA score reflects the extent of organ damage in relation to mortality, it might lack discriminative power in terms of whether the cause of organ damage was infection [5]. Moreover, the SOFA score calculation requires several laboratory test results, leading to a risk of delay in diagnosis and treatment [32].

WRS is an essential cytosolic aminoacyl-tRNA synthetase that is involved in the translation of mRNAs. WRS is secreted from monocytes, which play a key role in innate immunity, angiogenesis, and IFN-y signalling despite the exact pathways being unclear [33]. Ahn et al. reported that WRS emerges to act as a primary defence molecule against infection arising from interactions with Toll-like receptor 4 and myeloid differentiation factor 2 [16]. Furthermore, in a previous study, WRS was found to be immediately released and detected in the extracellular space within 1 hour of infection, and thus, it was concluded that WRS forms a part of the innate immune response in the early phase of viral infection [34]. Additionally, the secretion of WRS could be induced due to a variety of infectious pathogens including bacteria, fungi, or viruses [16]. Our study results showed better AUROC values for other clinical predictive factors of sepsis. It was not clear why the WRS level was associated with mortality due to sepsis in our study; therefore, further studies are required to determine whether the WRS level is valuable in mortality prediction and whether it could be used a novel treatment target.

This is the first study to analyse the value of WRS in a clinical patient sample with sepsis. Our results not only showed a higher sepsis discrimination power of WRS than that of other variables, but that WRS was also associated with 28-day overall mortality in ICU patients with sepsis. Therefore, the WRS level could be a new and powerful diagnostic marker for sepsis, and we consider that a high initial WRS level can be used to predict poor prognosis in critically ill patients with sepsis.

This study had several limitations. First, this study was a single-centre, retrospective study with a small sample size making generalisability of our results difficult. Therefore, a prospective multicentre study should be undertaken to confirm our findings. Second, there was a time difference between blood sampling and analysis, and protein degradation could have occurred prior to analysis. However, blood samples were aliquoted and stored in a refrigerator at $-80^{\circ} \mathrm{C}$ as soon as possible to prevent protein degradation, and we thawed the blood sample only once for analysis. Third, we could not analyse the serial results of WRS because we investigated the WRS level only once at the time of ICU admission. Further in vivo clinical trials with a randomised controlled, prospective design investigating the serial changes in the WRS level as a result of infection are needed.

\section{Conclusion}

We identified that WRS, a biomarker secreted owing to infectious stimuli, is useful for early detection of sepsis. Moreover, WRS is a more accurate predictive indicator of mortality in critically ill patients with sepsis than other scoring systems.

\section{Abbreviations}

APACHE II, Acute Physiology and Chronic Health Evaluation II; AKI, acute kidney injury; AUROC, area under the receiver operating characteristic; CLRs, C-type leptin receptors; CRP, C-reactive protein; Hct, haematocrit; ICU, intensive care unit; IL-6, Interleukin-6; IRB, Institutional Review Board; RDW, red cell distribution width; ROC, 
receiver operating characteristic; SOFA, Sequential Organ Failure Assessment; WBC, white blood cell; WRS, tryptophanyl-tRNA synthetase

\section{Declarations}

\section{Acknowledgements: None}

Ethical approval and consent to participate: The study protocol was approved by the institutional review board (IRB) of Severance Hospital (IRB number: 4-2017-0654, 4-2013-0585) for group of inflammation and sepsis. For the healthy control, the specimens used for this study were distributed by the Korea Institute of Radiological and Medical Sciences Radiation Biobank in the Republic of Korea (IRB number: P01-201803-31-006). Informed consent was waived because the study was retrospective in design.

Consent for publication: Not applicable.

Availability of data and materials: The datasets used and/or analysed during the current study are available from the corresponding author on reasonable request.

Competing interests: The authors declare that they have no competing interests.

\section{Funding: None}

Authors' contributions: KSC and BRY conceived and designed the study. All authors contributed to participant recruitment and data collection. JHS, SHL, AYL, MSP, and YSK described the usual care procedure and management. KSC, BRY, and JSC wrote the first draft of the manuscript. All the authors have evaluated the data, reviewed the manuscript, and have approved the final manuscript.

\section{References}

1. Martin GS, Mannino DM, Eaton S, Moss M. The epidemiology of sepsis in the United States from 1979 through 2000. N Engl J Med. 2003;348:1546-54.

2. Lever A, Mackenzie I. Sepsis: definition, epidemiology, and diagnosis. Bmj. 2007;335:879-83.

3. Shashikumar SP, Stanley MD, Sadiq I, Li Q, Holder A, Clifford GD, Nemati S. Early sepsis detection in critical care patients using multiscale blood pressure and heart rate dynamics. J Electrocardiol. 2017;50:739-43.

4. Seymour CW, Liu VX, Iwashyna TJ, Brunkhorst FM, Rea TD, Scherag A, Rubenfeld G, Kahn JM, Shankar-Hari M, Singer M, Deutschman CS, Escobar GJ, Angus DC. Assessment of Clinical Criteria for Sepsis: For the Third International Consensus Definitions for Sepsis and Septic Shock (Sepsis-3). Jama. 2016;315:762-74.

5. Klimpel J, Weidhase L, Bernhard M, Gries A, Petros S. The impact of the Sepsis-3 definition on ICU admission of patients with infection. Scand J Trauma Resusc Emerg Med. 2019;27:98.

6. Cui N, Zhang H, Chen Z, Yu Z. Prognostic significance of PCT and CRP evaluation for adult ICU patients with sepsis and septic shock: retrospective analysis of 59 cases. J Int Med Res. 2019;47:1573-9.

7. Wu Q, Yang H, Kang Y. Combined assessment of DeltaPCT and DeltaCRP could increase the ability to differentiate candidemia from bacteremia. Crit Care. 2019;23:271. 
8. Vijayan AL, Vanimaya, Ravindran S, Saikant R, Lakshmi S, Kartik R, G M. Procalcitonin: a promising diagnostic marker for sepsis and antibiotic therapy. J Intensive Care. 2017;5:51.

9. Wiersinga WJ, Leopold SJ, Cranendonk DR, van der Poll T. Host innate immune responses to sepsis. Virulence. 2014;5:36-44.

10. Akira S, Uematsu S, Takeuchi O. Pathogen Recognition and Innate Immunity. Cell. 2006;124:783-801.

11. Kumar H, Kawai T, Akira S. Pathogen Recognition by the Innate Immune System. International Reviews of Immunology. 2011;30:16-34.

12. Jobin PG, Solis N, Machado Y, Bell PA, Kwon NH, Kim S, Overall CM, Butler GS. Matrix metalloproteinases inactivate the proinflammatory functions of secreted moonlighting tryptophanyl-tRNA synthetase. J Biol Chem. 2019;294:12866-79.

13. Simmen KA, Singh J, Luukkonen BG, Lopper M, Bittner A, Miller NE, Jackson MR, Compton T, Fruh K. Global modulation of cellular transcription by human cytomegalovirus is initiated by viral glycoprotein $\mathrm{B}$. Proc Natl Acad Sci U S A. 2001;98:7140-5.

14. Wieland S, Thimme R, Purcell RH, Chisari FV. Genomic analysis of the host response to hepatitis B virus infection. Proc Natl Acad Sci U S A. 2004;101:6669-74.

15. Ellis CN, LaRocque RC, Uddin T, Krastins B, Mayo-Smith LM, Sarracino D, Karlsson EK, Rahman A, Shirin T, Bhuiyan TR, Chowdhury F, Khan Al, Ryan ET, Calderwood SB, Qadri F, Harris JB. Comparative proteomic analysis reveals activation of mucosal innate immune signaling pathways during cholera. Infect Immun. 2015;83:1089-103.

16. Ahn YH, Park S, Choi JJ, Park BK, Rhee KH, Kang E, Ahn S, Lee CH, Lee JS, Inn KS, Cho ML, Park SH, Park K, Park HJ, Lee JH, Park JW, Kwon NH, Shim H, Han BW, Kim P, Lee JY, Jeon Y, Huh JW, Jin M, Kim S. Secreted tryptophanyl-tRNA synthetase as a primary defence system against infection. Nat Microbiol. 2016;2:16191.

17. Levy MM, Evans LE, Rhodes A. The Surviving Sepsis Campaign Bundle: 2018 Update. Crit Care Med. 2018;46:997-1000.

18. Filbin MR, Arias SA, Camargo CA, Jr., Barche A, Pallin DJ. Sepsis visits and antibiotic utilization in U.S. emergency departments*. Crit Care Med. 2014;42:528-35.

19. Liu HH, Zhang MW, Guo JB, Li J, Su L. Procalcitonin and C-reactive protein in early diagnosis of sepsis caused by either Gram-negative or Gram-positive bacteria. Irish Journal of Medical Science (1971 -). 2017;186:207-12.

20. Miguel-Bayarri V, Casanoves-Laparra EB, Pallas-Beneyto L, Sancho-Chinesta S, Martin-Osorio LF, TormoCalandin C, Bautista-Rentero D. Prognostic value of the biomarkers procalcitonin, interleukin- 6 and C-reactive protein in severe sepsis. Med Intensiva. 2012;36:556-62.

21. Uusitalo-Seppala R, Koskinen P, Leino A, Peuravuori H, Vahlberg T, Rintala EM. Early detection of severe sepsis in the emergency room: diagnostic value of plasma C-reactive protein, procalcitonin, and interleukin- 6. Scand J Infect Dis. 2011;43:883-90.

22. Giannakopoulos K, Hoffmann U, Ansari U, Bertsch T, Borggrefe M, Akin I, Behnes M. The Use of Biomarkers in Sepsis: A Systematic Review. Curr Pharm Biotechnol. 2017;18:499-507.

23. Pregernig A, Muller M, Held U, Beck-Schimmer B. Prediction of mortality in adult patients with sepsis using six biomarkers: a systematic review and meta-analysis. Ann Intensive Care. 2019;9:125. 
24. Sandquist M, Wong HR. Biomarkers of sepsis and their potential value in diagnosis, prognosis and treatment. Expert Rev Clin Immunol. 2014;10:1349-56.

25. Póvoa P, Salluh JIF. Biomarker-guided antibiotic therapy in adult critically ill patients: a critical review. Annals of Intensive Care. 2012;2:32.

26. Wacker C, Prkno A, Brunkhorst FM, Schlattmann P. Procalcitonin as a diagnostic marker for sepsis: a systematic review and meta-analysis. Lancet Infect Dis. 2013;13:426-35.

27. Cortegiani A, Misseri G, Ippolito M, Bassetti M, Giarratano A, Martin-Loeches I, Einav S. Procalcitonin levels in candidemia versus bacteremia: a systematic review. Crit Care. 2019;23:190.

28. Yunus I, Fasih A, Wang Y. The use of procalcitonin in the determination of severity of sepsis, patient outcomes and infection characteristics. PLoS One. 2018;13:e0206527.

29. Schuetz P, Birkhahn R, Sherwin R, Jones AE, Singer A, Kline JA, Runyon MS, Self WH, Courtney DM, Nowak RM, Gaieski DF, Ebmeyer S, Johannes S, Wiemer JC, Schwabe A, Shapiro NI. Serial Procalcitonin Predicts Mortality in Severe Sepsis Patients: Results From the Multicenter Procalcitonin MOnitoring SEpsis (MOSES) Study. Crit Care Med. 2017;45:781-9.

30. Raith EP, Udy AA, Bailey M, McGloughlin S, Maclsaac C, Bellomo R, Pilcher DV. Prognostic Accuracy of the SOFA Score, SIRS Criteria, and qSOFA Score for In-Hospital Mortality Among Adults With Suspected Infection Admitted to the Intensive Care Unit. Jama. 2017;317:290-300.

31. Rhee C, Klompas M. New Sepsis and Septic Shock Definitions: Clinical Implications and Controversies. Infect Dis Clin North Am. 2017;31:397-413.

32. Verdonk F, Blet A, Mebazaa A. The new sepsis definition: limitations and contribution to research and diagnosis of sepsis. Curr Opin Anaesthesiol. 2017;30:200-4.

33. Jin M. Unique roles of tryptophanyl-tRNA synthetase in immune control and its therapeutic implications. Exp Mol Med. 2019;51:1.

34. Lee HC, Lee ES, Uddin MB, Kim TH, Kim JH, Chathuranga K, Chathuranga WAG, Jin M, Kim S, Kim CJ, Lee JS. Released Tryptophanyl-tRNA Synthetase Stimulates Innate Immune Responses against Viral Infection. J Virol. 2019;93.

\section{Tables}




\begin{tabular}{|c|c|c|c|c|}
\hline & Inflammation & Sepsis & Total & P-value \\
\hline & $N=51(21.2 \%)$ & $N=190(78.8 \%)$ & $N=241(100 \%)$ & \\
\hline Age (year) & $69(58,78)$ & $69(57,77)$ & $69(57,77)$ & 0.954 \\
\hline Sex (male), n (\%) & $23(45.1)$ & $67(35.3)$ & $151(62.7)$ & 0.198 \\
\hline BMI $\left(\mathrm{kg} / \mathrm{m}^{2}\right)$ & $20.8(17.6,24.5)$ & $21.5(19.0,24.6)$ & $21.4(18.7,24.5)$ & 0.298 \\
\hline Smoking, n (\%) & $15(29.4)$ & $59(31.1)$ & $74(30.7)$ & 0.917 \\
\hline $\mathrm{CCl}$ & $3(1,4)$ & $3(2,5)$ & $3(2,5)$ & 0.061 \\
\hline \multicolumn{5}{|l|}{ Comorbidity disease, n (\%) } \\
\hline Congestive heart failure & $7(13.7)$ & $34(17.9)$ & $41(17.0)$ & 0.483 \\
\hline Coronary arterial disease & $8(15.7)$ & $27(14.2)$ & $35(14.5)$ & 0.791 \\
\hline Chronic pulmonary disease & $9(17.6)$ & $27(14.2)$ & $36(14.9)$ & 0.542 \\
\hline Chronic kidney disease & $11(21.6)$ & $57(30.0)$ & $68(28.2)$ & 0.236 \\
\hline Chronic liver disease & $12(23.5)$ & $37(19.5)$ & $49(20.3)$ & 0.524 \\
\hline Cerebrovascular disease & $7(13.7)$ & $33(17.4)$ & $40(16.6)$ & 0.536 \\
\hline Solid cancer & $13(25.5)$ & $56(29.5)$ & $69(28.6)$ & 0.577 \\
\hline Hematologic malignancy & $3(5.9)$ & $13(6.8)$ & $16(6.6)$ & 0.807 \\
\hline AKI, n (\%) & $12(23.5)$ & $87(45.8)$ & $99(41.1)$ & 0.004 \\
\hline \multicolumn{5}{|l|}{ Clinical parameters } \\
\hline Mean arterial pressure $(\mathrm{mmHg})$ & $90(75,97)$ & $73(60,100)$ & $76(62,97)$ & 0.008 \\
\hline Heart rate (beats/min) & $96(80,107)$ & $113(97,130)$ & $107(92,127)$ & $<0.001$ \\
\hline WBC $\left(\times 10^{3} / \mu \mathrm{L}\right)$ & $12.7(5.6,18.8)$ & $12.2(6.61,19.3)$ & $12.4(6.44,19.22)$ & 0.641 \\
\hline Hct (\%) & $29.0(25.6,33.8)$ & $28.2(24.2,33.8)$ & $28.7(24.5,33.7)$ & 0.302 \\
\hline RDW (\%) & $14.8(13.6,16.5)$ & $15.6(14.4,16.9)$ & $15.4(14.3,16.8)$ & 0.016 \\
\hline Platelet $\left(\times 10^{3} / \mu \mathrm{L}\right)$ & $191(139,276)$ & $118(52,202)$ & $137(70,220)$ & $<0.001$ \\
\hline BUN (mg/dL) & $20.5(14.2,38.0)$ & $34.2(21.6,52.3)$ & $31.7(19.7,51.0)$ & 0.001 \\
\hline Creatinine (mg/dL) & $0.87(0.45,2.29)$ & $1.61(0.76,2.86)$ & $1.43(0.66,2.80)$ & 0.003 \\
\hline Albumin (g/dL) & $2.6(2.3,3.1)$ & $2.4(2.1,2.7)$ & $2.4(2.1,2.8)$ & 0.004 \\
\hline Total bilirubin (mg/dL) & $0.6(0.4,0.8)$ & $0.8(0.4,1.3)$ & $0.7(0.4,1.2)$ & 0.025 \\
\hline Sodium (mmol/L) & $138(134,141)$ & $138(134,142)$ & $138(134,141)$ & 0.574 \\
\hline Potassium (mmol/L) & $3.8(3.5,4.3)$ & $3.8(3.3,4.5)$ & $3.8(3.4,4.4)$ & 0.942 \\
\hline Lactate (mmol/L) & $1.7(1.1,2.5)$ & $2.5(1.5,5.1)$ & $2.3(1.4,4.0)$ & $<0.001$ \\
\hline
\end{tabular}


Table 1. Baseline characteristics and clinical parameters of ICU cohort patients.

Values are expressed as $\mathrm{n}(\%)$ or median (interquartile range) unless otherwise indicated.

AKI, acute kidney injury; BMI, body mass index; $\mathrm{BUN}$, blood urea nitrogen; $\mathrm{CCl}$, Charlson comorbidity index; Hct, haematocrit; ICU, intensive care unit; RDW, red cell distribution width; WBC, white blood cell

\begin{tabular}{|c|c|c|c|c|c|}
\hline & $\begin{array}{l}\text { Healthy } \\
\text { control }\end{array}$ & Inflammation & Sepsis & Total & P-value \\
\hline & $N=127$ & $\mathrm{~N}=51(21.2 \%)$ & $\begin{array}{l}N=190 \\
(78.8 \%)\end{array}$ & $\begin{array}{l}N=241 \\
(100 \%)\end{array}$ & \\
\hline WRS (ng/mL) & $\begin{array}{l}18.36(14.21 \\
24.14)\end{array}$ & $\begin{array}{l}44.04(33.58, \\
54.07)\end{array}$ & $\begin{array}{l}86.60(63.61 \\
121.56)\end{array}$ & $\begin{array}{l}73.32(52.29 \\
110.41)\end{array}$ & $<0.001$ \\
\hline РCT $(\mathrm{ng} / \mathrm{mL})$ & & $\begin{array}{l}0.40(0.13 \\
2.08)\end{array}$ & $\begin{array}{l}2.82(0.70 \\
15.15)\end{array}$ & $\begin{array}{l}2.02(0.46 \\
12.13)\end{array}$ & $<0.001$ \\
\hline CRP (mg/L) & $\begin{array}{l}0.06(0.03 \\
0.14)\end{array}$ & $\begin{array}{l}8.46(2.38 \\
15.38)\end{array}$ & $\begin{array}{l}12.92(5.62, \\
21.85)\end{array}$ & $\begin{array}{l}12.09(4.70 \\
21.00)\end{array}$ & 0.006 \\
\hline IL-6 (pg/mL) & $\begin{array}{l}2.01(1.15 \\
3.13)\end{array}$ & $\begin{array}{l}109.00(28.73, \\
374.60)\end{array}$ & $\begin{array}{l}282.00(63.16 \\
533.35)\end{array}$ & $\begin{array}{l}212.50(49.87 \\
522.85)\end{array}$ & 0.001 \\
\hline SOFA & & $6(4,8)$ & $10(8,13)$ & $9(7,12)$ & $<0.001$ \\
\hline APACHE II & & $19(13,24)$ & $27(21,34)$ & $25(18,32)$ & $<0.001$ \\
\hline $\begin{array}{l}28 \text { days mortality, (non- } \\
\text { survivors), } n(\%)\end{array}$ & & $7(13.7)$ & $68(35.8)$ & $75(31.1)$ & 0.003 \\
\hline $\begin{array}{l}60 \text { days mortality, (non- } \\
\text { survivors), } n(\%)\end{array}$ & & $9(17.6)$ & $81(42.6)$ & $90(37.3)$ & 0.001 \\
\hline $\begin{array}{l}90 \text { days mortality, (non- } \\
\text { survivors), } n(\%)\end{array}$ & & $10(19.6)$ & $84(44.2)$ & $94(39.0)$ & 0.001 \\
\hline ICU length of stay (days) & & $6(3,11)$ & $9(4,17)$ & $8(3,15)$ & 0.039 \\
\hline ICU free days (days) & & $21(13,24)$ & $11(0,21)$ & $15(0,22)$ & $<0.001$ \\
\hline $\begin{array}{l}\text { ICU mortality, (non- } \\
\text { survivors), } \mathrm{n}(\%)\end{array}$ & & $9(17.6)$ & $68(35.8)$ & $77(32.0)$ & 0.014 \\
\hline $\begin{array}{l}\text { Hospital mortality, (non- } \\
\text { survivors), } \mathrm{n}(\%)\end{array}$ & & $14(27.5)$ & $89(46.8)$ & $103(42.7)$ & 0.013 \\
\hline
\end{tabular}

Table 2. Biomarkers and clinical outcomes 
Values are expressed as $\mathrm{n}(\%)$ or median (interquartile range) unless otherwise indicated.

APACHE II, acute physiology and chronic health evaluation score II; CRP, C-reactive protein; ICU, intensive care unit; IL-6, interleukin-6; PCT, procalcitonin; SOFA, sequential organ failure assessment; WRS, tryptophanyl-tRNA synthetase;

\begin{tabular}{|c|c|c|c|c|c|c|c|c|c|}
\hline & AUC & SE & $\begin{array}{l}P \\
\text { value }\end{array}$ & $\begin{array}{l}95 \% \\
\mathrm{Cl}\end{array}$ & Cutoff & Sensitivity & Specificity & $\begin{array}{l}\begin{array}{l}\text { AUC } \\
\text { different }\end{array} \\
\text { compared } \\
\text { to WRS }\end{array}$ & $\begin{array}{l}\mathrm{P} \\
\text { value }\end{array}$ \\
\hline WRS & 0.864 & 0.029 & $<0.001$ & $\begin{array}{l}0.807- \\
0.922\end{array}$ & 54.34 & 0.868 & 0.765 & Reference & \\
\hline РCT & 0.727 & 0.041 & $<0.001$ & $\begin{array}{l}0.647- \\
0.807\end{array}$ & 0.42 & 0.842 & 0.510 & 0.137 & 0.013 \\
\hline CRP & 0.625 & 0.045 & 0.006 & $\begin{array}{l}0.537- \\
0.713\end{array}$ & 13.74 & 0.474 & 0.745 & 0.239 & $<0.001$ \\
\hline IL-6 & 0.651 & 0.042 & 0.001 & $\begin{array}{l}0.568- \\
0.733\end{array}$ & 196.95 & 0.563 & 0.686 & 0.213 & $<0.001$ \\
\hline SOFA & 0.840 & 0.029 & $<0.001$ & $\begin{array}{l}0.784- \\
0.896\end{array}$ & 8 & 0.684 & 0.863 & 0.024 & 0.576 \\
\hline $\begin{array}{l}\text { APACHE } \\
\text { II }\end{array}$ & 0.754 & 0.036 & $<0.001$ & $\begin{array}{l}0.684- \\
0.825\end{array}$ & 20 & 0.763 & 0.627 & 0.110 & 0.021 \\
\hline
\end{tabular}

Table 3. The area under receiver operative characteristics (AUROC) for sepsis discrimination

WRS, Tryptophanyl-tRNA synthetase; PCT, Procalcitonin; CRP, C-Reactive Protein; IL-6, Interleukin-6; SOFA, Sequential Organ Failure Assessment; APACHE II, Acute Physiology and Chronic Health Evaluation Score II; ICU, Intensive Care Unit 


\begin{tabular}{|llllllllll|}
\hline & AUC & SE & $\begin{array}{l}\text { P } \\
\text { value }\end{array}$ & $95 \%$ Cl & Cutoff & Sensitivity & Specificity & $\begin{array}{l}\text { AUC } \\
\text { different } \\
\text { compared } \\
\text { to WRS }\end{array}$ & $\begin{array}{l}\text { Palue } \\
\text { value }\end{array}$ \\
\hline WRS & 0.687 & 0.042 & $<0.001$ & $\begin{array}{l}0.604- \\
0.770\end{array}$ & 97.23 & 0.647 & 0.721 & Reference & \\
\hline PCT & 0.519 & 0.044 & 0.672 & $\begin{array}{l}0.433- \\
0.604\end{array}$ & 1.97 & 0.618 & 0.459 & 0.168 & 0.006 \\
\hline CRP & 0.436 & 0.043 & 0.141 & $\begin{array}{l}0.351- \\
0.520\end{array}$ & 29.08 & 0.132 & 0.877 & 0.251 & 0.023 \\
\hline IL-6 & 0.611 & 0.041 & 0.011 & $\begin{array}{l}0.530- \\
0.692\end{array}$ & 92.78 & 0.853 & 0.410 & 0.076 & 0.173 \\
\hline SOFA & 0.711 & 0.040 & $<0.001$ & $\begin{array}{l}0.632- \\
0.790\end{array}$ & 12 & 0.500 & 0.861 & -0.024 & 0.650 \\
\hline $\begin{array}{l}\text { APACHE } \\
\text { II }\end{array}$ & 0.666 & 0.042 & $<0.001$ & $\begin{array}{l}0.583- \\
0.749\end{array}$ & 28 & 0.632 & 0.656 & 0.021 & 0.725 \\
\hline
\end{tabular}

Table 4. The area under receiver operative characteristics (AUROC) for 28 days mortality of sepsis patients $(\mathrm{N}=190)$

WRS, Tryptophanyl-tRNA synthetase; PCT, Procalcitonin; CRP, C-Reactive Protein; IL-6, Interleukin-6; SOFA, Sequential Organ Failure Assessment; APACHE II, Acute Physiology and Chronic Health Evaluation Score II; ICU, Intensive Care Unit

\section{Figures}




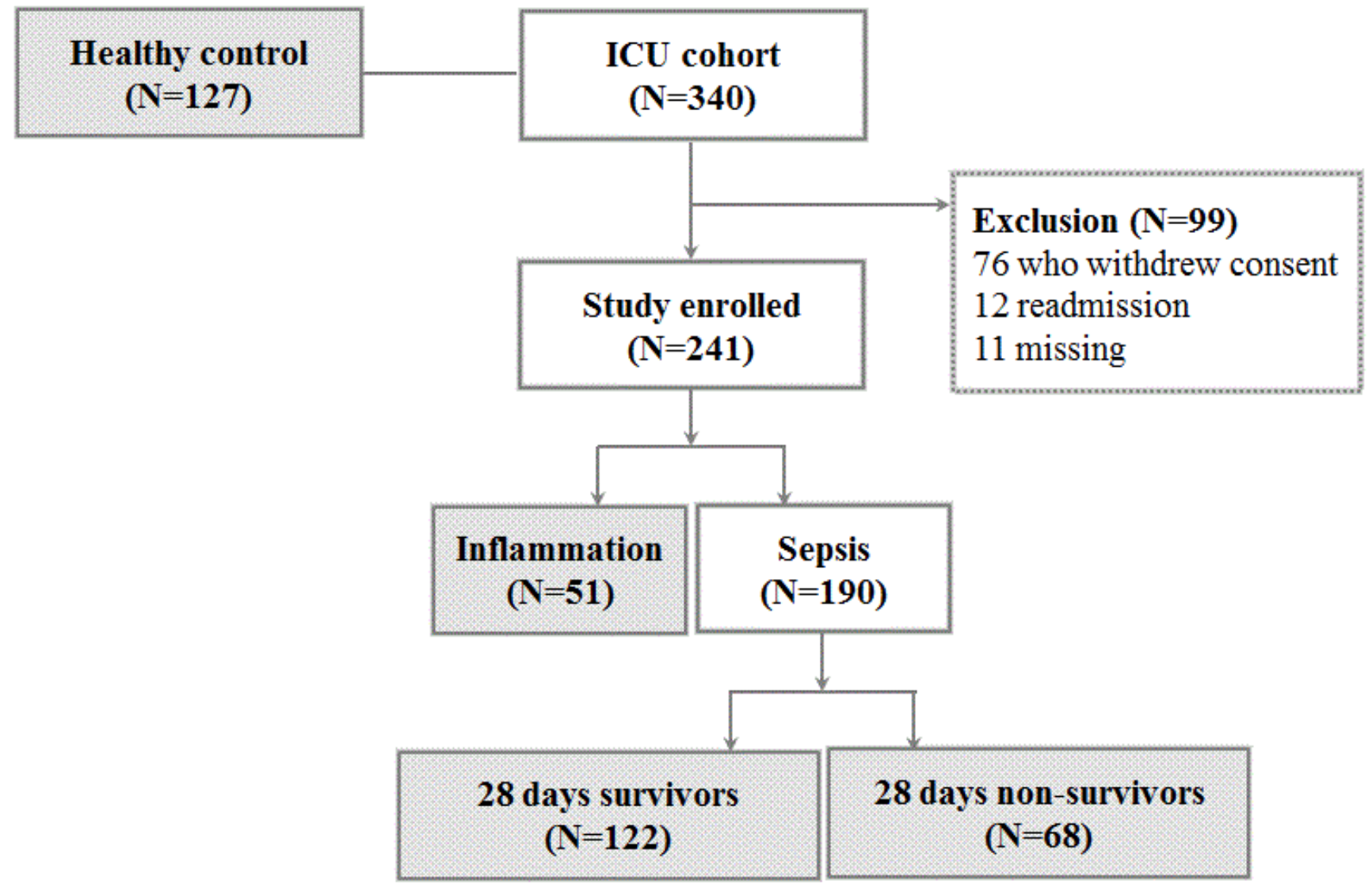

Figure 2

Study flow 


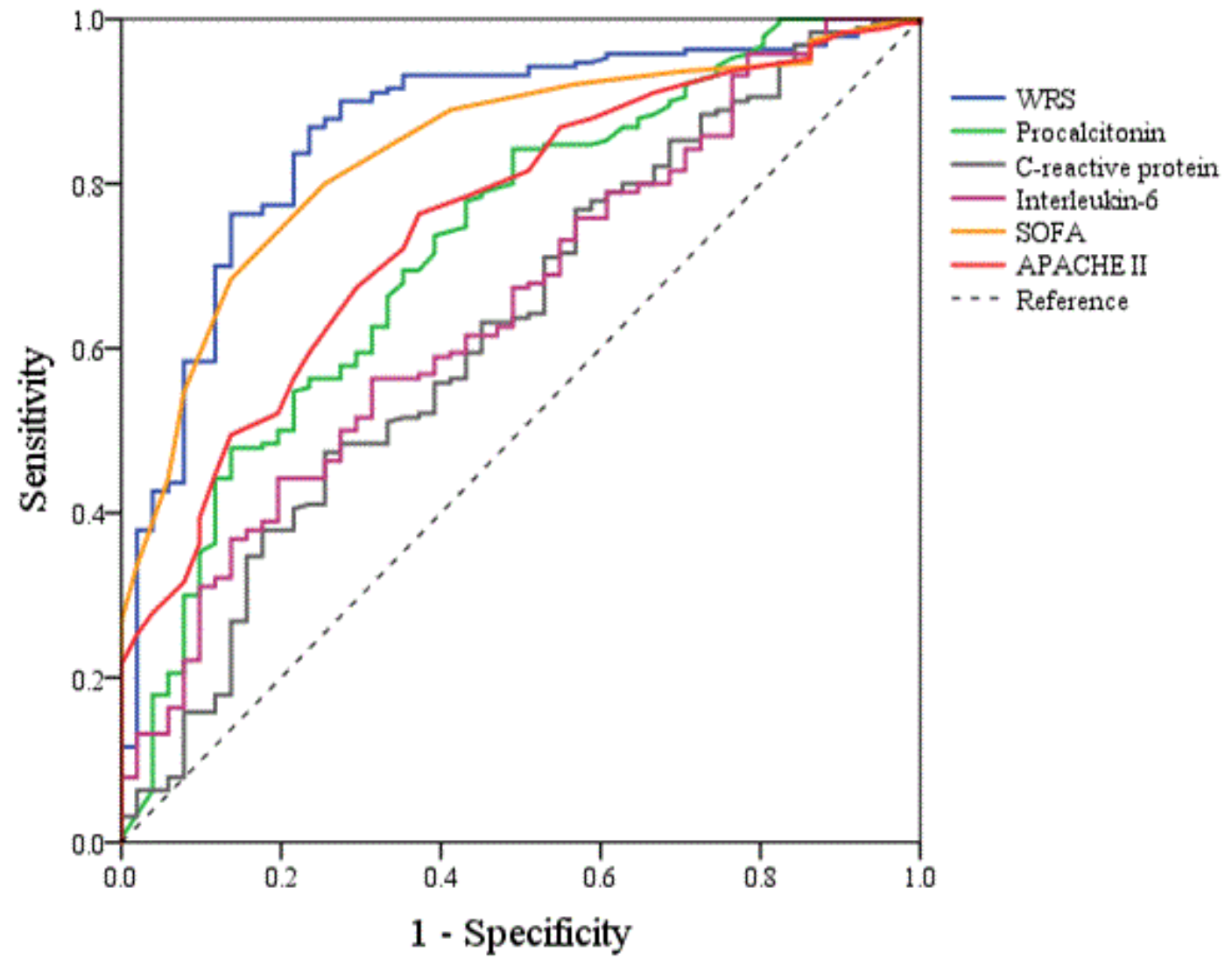

Figure 4

The area under receiver operating characteristics (AUROC) for sepsis discrimination 


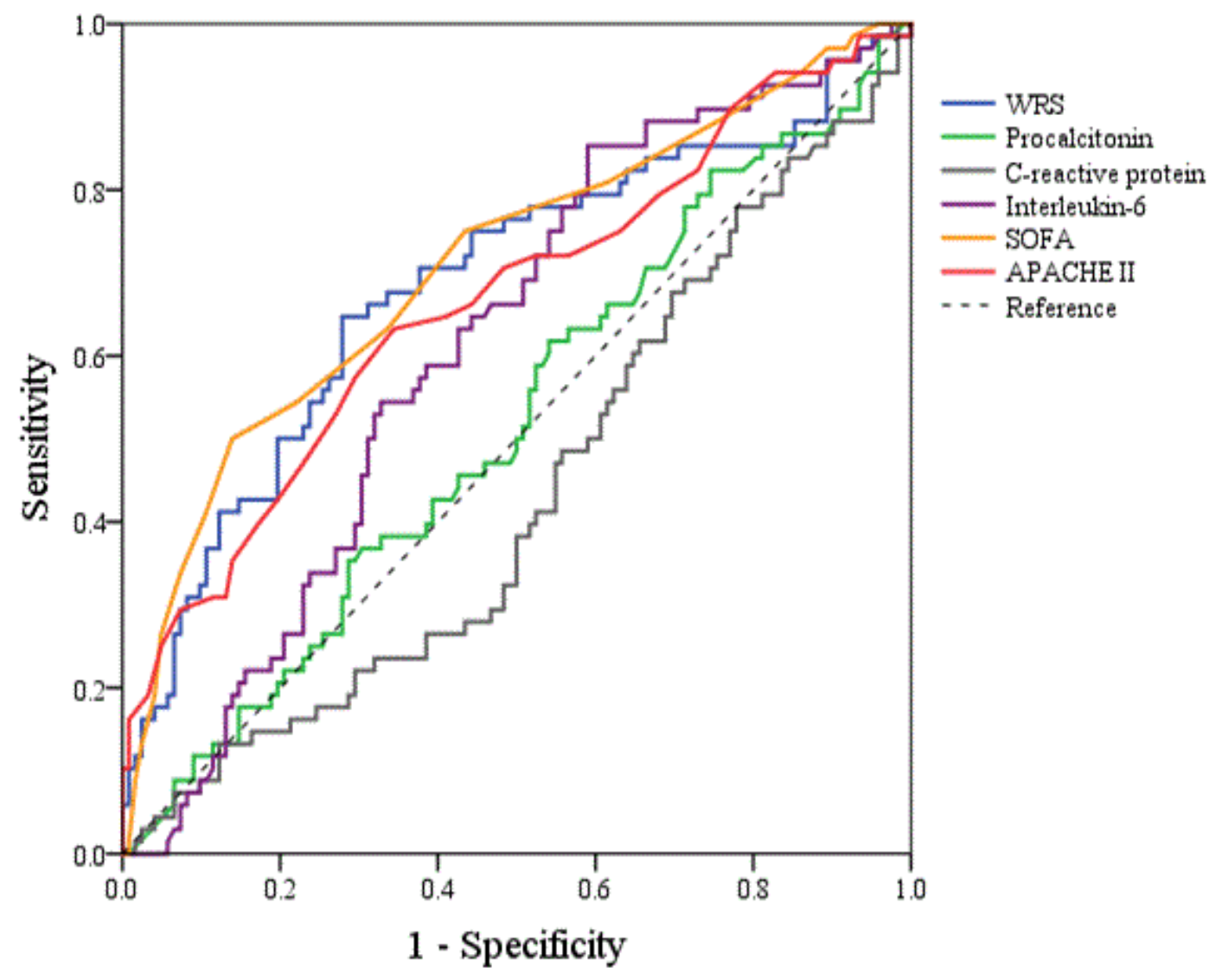

Figure 6

The area under receiver operating characteristics (AUROC) for 28-day mortality in patients with sepsis $(\mathrm{N}=190)$ 


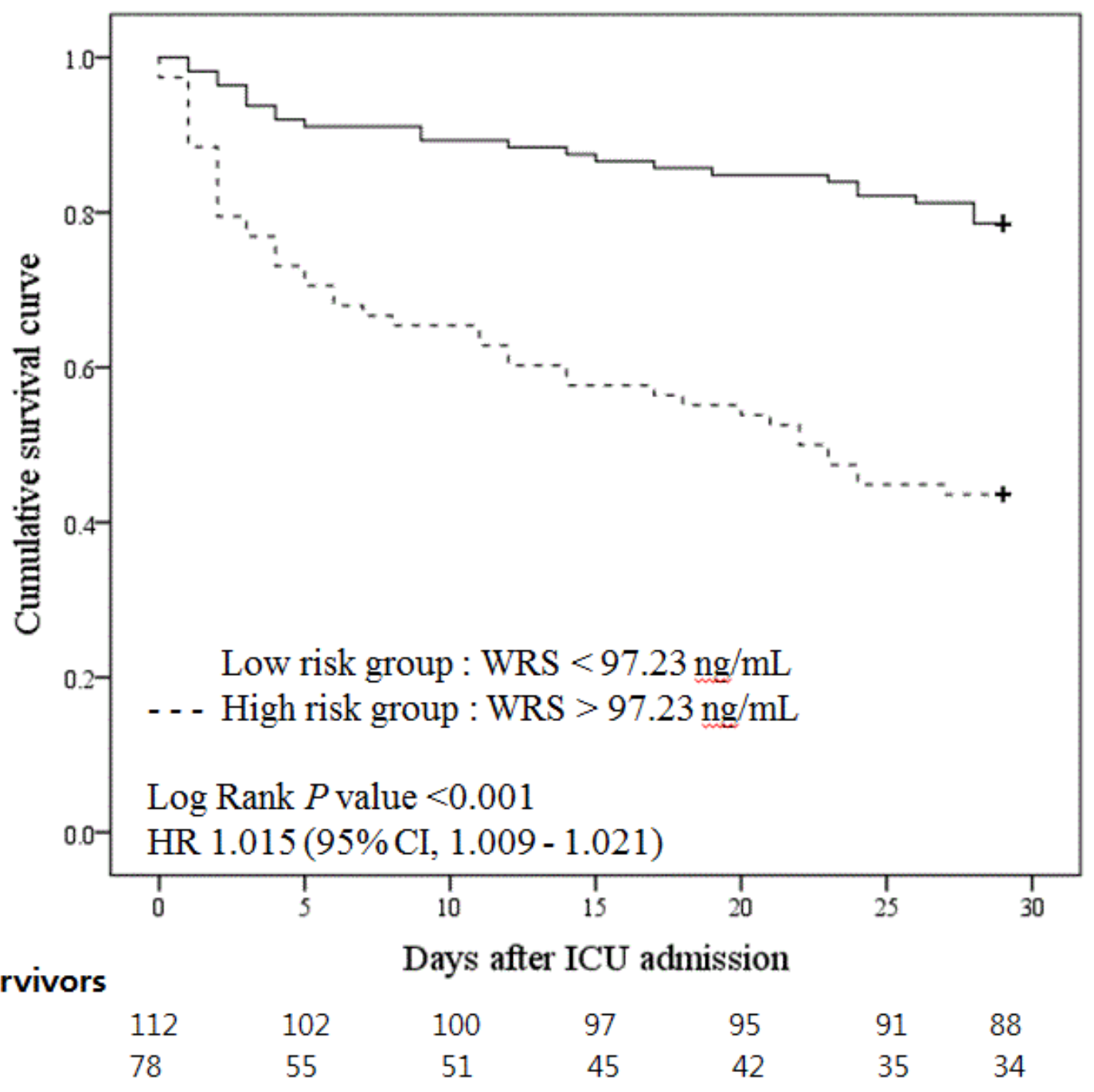

Figure 8

28-day survival rate in patients with sepsis $(\mathrm{N}=190)$ 